DOI: https://doi.org/10.47405/mjssh.v6i8.945

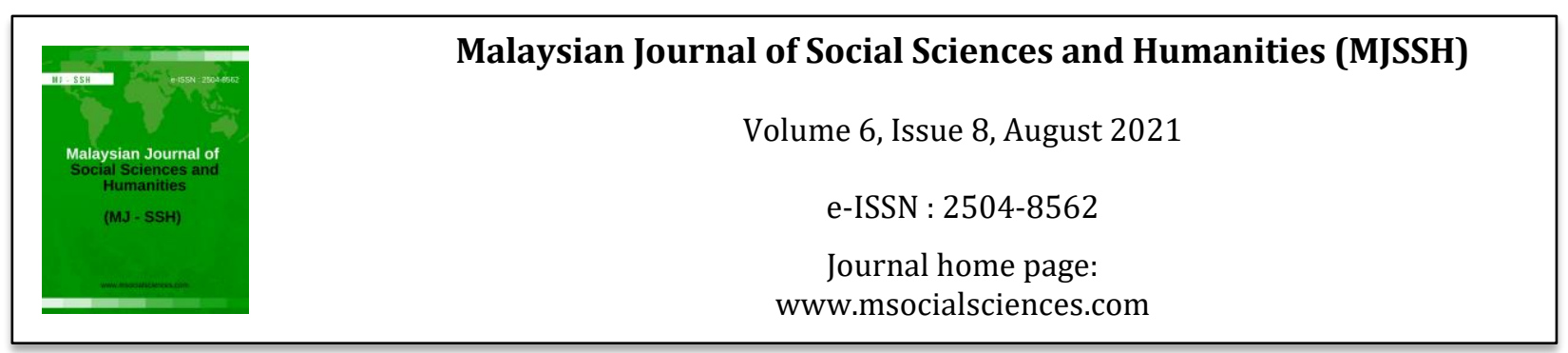

\title{
Efikasi Kendiri dan Keterlibatan Pelajar Belajar dalam Talian Sepanjang Tempoh Kawalan Pergerakan COVID-19
}

\author{
Faris Jazli Bin Jamidi' ${ }^{1}$, Shahlan Surat ${ }^{1}$ \\ ${ }^{1}$ Fakulti Pendidikan, Universiti Kebangsaan Malaysia (UKM) \\ Correspondence: Faris Jazli (farishjazli@gmail.com)
}

\begin{abstract}
Abstrak
Wabak Covid-19 telah memberi kesan kepada landskap mod pengajaran dan pembelajaran secara bersemuka kepada dalam talian sepenuhnya dengan persediaan dan kemahiran yang minimum. Kajian ini meninjau sejauh mana hubungan efikasi kendiri pelajar belajar secara dalam talian dan keterlibatan pelajar. Dalam proses perubahan mod pembelajaran ini, efikasi kendiri pelajar dan penglibatan pelajar dalam talian menjadi antara elemen yang perlu diberikan perhatian. Kajian menggunakan reka bentuk tinjauan dijalankan kepada 219 pelajar sarjana dari Fakulti Pendidikan Universiti Kebangsaan Malaysia yang mengambil kursus secara dalam talian sepanjang tempoh kawalan pergerakan pandemik Covid19. Data dikumpulkan menggunakan borang soal selidik Pembelajaran Dalam Talian Sepanjang tempoh Kawalan Pergerakan digunakan untuk mengukur tahap efikasi kendiri pelajar belajar secara dalam talian dan keterlibatan pelajar. Data dianalisis menggunakan statistik deskriptif dan inferensi. Dapatan kajian menunjukkan, skor bagi efikasi kendiri dan skor penglibatan pelajar adalah tinggi. Hasil analisa korelasi Pearson menunjukkan bahawa terdapat hubungan yang signifikan antara efikasi kendiri dan penglibatan pelajar dalam talian. Hasil kajian ini dijangka dapat membantu pihak berautoriti yang berkaitan bagi menyusun strategi terbaik dalam pelaksanaan pengajaran dalam talian supaya mampu menjadi alternatif dan pelengkap bagi pembelajaran bersemuka.
\end{abstract}

Kata kunci: efikasi kendiri, penglibatan pelajar, keyakinan, pembelajaran dalam talian, pandemik Covid-19

\section{Self-Efficacy in Online Learning in Relation with Student's Engagement}

\begin{abstract}
The Covid-19 pandemic has transformed the landscape conventional teaching and learning into completely online with minimal preparation and skills. Therefore, the purpose of this study is to examine the extent of the relationship between self-efficacy of students studying online and student's engagement. As for quantitative approach, survey was used in this study. A total of 219 postgraduate students from the Faculty of Education University Kebangsaan Malaysia who took online courses as respondent of the study. Questionnaire forms as research instruments were used to measure perception of self-efficacy of students when learning online and student's engagement. Data were collected using google form to survey online learning during movement control order. The, data were analyzed using descriptive and inferential statistics. The findings show that the score for students' self-efficacy and student involvement were high. The results of pearson correlation analysis showed that there was a significant relationship between self-efficacy and student engagement. The results of this study are
\end{abstract}


expected to help students, lecturers, the university and the Ministry of Higher Education formulate the best strategies in the implementation of online teaching pedagogy

Keywords: self-efficacy, student engagement, confidence, online learning readiness, pandemic Covid19.

\section{Pengenalan}

Pandemik Covid-19 melanda di seluruh pelosok dunia dengan sangat pantas yang menyebabkan jutaan kematian pada tahun pertama dikenal pasti. Cara yang terbaik mengatasi pandemik ini adalah dengan penjarakan fizikal serta perintah kawalan pergerakan bagi mengekang covid-19 merebak dengan lebih teruk. Hal ini menyebabkan, semua industri termasuk bidang pendidikan terpaksa ditutup dan terkesan dengan perintah kawalan pergerakan ini. Pihak berwajib, khususnya bahagian pendidikan melakukan usaha yang bersepadu dalam mengekalkan agenda pendidikan dapat dijalankan walaupun ketika kawalan pergerakan dijalankan dengan medium alternatif seperti televisyen, radio, dan internet.

Penutupan institusi pendidikan dibuat secara mendadak di semua peringkat yang menyebabkan pada pendidik, guru, pelajar terpaksa beralih ke pembelajaran atas talian dengan persiapan yang kurang. Persiapan ini adalah termasuk dari kesediaan platform e-pembelajaran, kemahiran teknikal, kemahiran pengajaran, penilaian atau pentaksiran dan sebagainya. Hal ini disokong oleh Carey (2020), pendidikan atas talian ini menyebabkan pedagogi berubah secara keseluruhan dalam masa singkat, oleh itu, institusi pendidikan perlu mengadaptasi ke pembelajaran atas talian dalam skala besar. Kesediaan yang baik, termasuklah efikasi kendiri dalam pembelajaran secara atas talian, Efikasi kendiri akan memberi kesan terhadap perjalanan kelas dan objektif pengajaran. Namun dalam proses transisi ini, terdapat juga masalah keciciran dan pelajar dalam keadaan tertekan ketika terpaksa menghadapi perubahan yang mendadak dalam menghadapi norma baharu.

Menurut Radhal et al. (2020) dan Harish et al. (2020) pembelajaran dalam talian menjadi pilihan yang relevan dan sesuai untuk memastikan pembelajaran dapat diteruskan dan mengelakkan penangguhan kalendar akademik. Peningkatan kursus dalam talian dan metodologi pengajaran dalam talian perlu diteliti sejauh mana pelajar bersedia atau tidak bersedia menggunakan pendekatan terbaru ini Dengan maklumat yang mencukupi, pihak terlibat dapat memudahkan institusi untuk merancang pelaksanaan pembelajaran dalam talian dengan berkesan ke dalam kurikulumnya.

Pelajar harus menyesuaikan diri dengan transisi ke pembelajaran norma baharu dan perlu meneruskan penyampaian pengajaran dan pembelajaran yang berlaku sepenuhnya secara dalam talian. Menurut Hung et al, (2010) memahami kesediaan pelajar yang mengambil kelas dalam talian dapat membantu meningkatkan kejayaan pelajar dalam talian dan membantu guru membangunkan pelajar secara dalam talian. Selain itu, dalam proses perubahan mod pembelajaran ini, efikasi kendiri pelajar menjadi antara elemen yang perlu diberikan perhatian kerana walaupun pelajar zaman milenium didedahkan dengan teknologi dan mahir dalam dunia digital, namun, menurut Comer, Lenaghan dan Sengupta (2015) menyatakan tanpa efikasi kendiri yang baik, ia akan memberi kesan kepada pembelajaran dalam talian dan selain itu pelajar juga perlu menyesuaikan diri untuk terlibat secara aktif ketika sesi pembelajaran. Kemahiran komputer mampu memberi kesan kepada pembelajaran dalam talian. Menurut Araya dan Hayley (2019), menyatakan terdapat korelasi antara pengetahuan komputer dan efikasi kendiri pembelajaran dalam talian. Teknologi dapat membantu menjadikan pembelajaran lebih menarik agar menarik minat pelajar untuk terlibat aktif dalam sesi pembelajaran. Menurut Norazlinda and Surendran (2020) kemahiran menggunakan teknologi membantu pelajar dan guru dan pelajar meneroka dengan lebih luas kemudahan yang relevan dengan pembelajaran, Walau bagaimanapun, masih kurang kajian berkaitan pembelajaran dalam talian bagi pelajar universiti di Malaysia walaupun pembelajaran dalam talian sudah dipraktikkan dalam sebahagian institut pengajian tinggi. Dimensi efikasi kendiri dan penglibatan pelajar dalam talian perlu diberi perhatian agar pelaksanaan pembelajaran dan pengajaran kekal relevan dan berkesan. 
Kajian ini dilaksanakan bagi mengenal pasti tahap efikasi pelajar belajar dalam talian dan keterlibatan pelajar dalam pembelajaran atas talian serta hubungan antara dua pemboleh ubah kajian ini dilaksanakan kepada pelajar pascasiswazah Fakulti Pendidikan Universiti Kebangsaan Malaysia (UKM) yang mengambil kursus secara dalam talian sepenuhnya sepanjang tempoh kawalan pergerakan (selepas Mac 2020 sehingga Ogos 2021). Pelajar sarjana Fakulti Pendidikan UKM merupakan kumpulan yang teramai berbanding fakulti lain. Pelajar yang terlibat adalah termasuk pelajar sepenuh masa ,separuh masa, mod kajian penuh, mod campuran dan mod kursus. Diharap melalui kajian ini dapat memberi manfaat kepada pihak berkaitan seperti pelajar, pensyarah, pihak universiti, institusi pendidikan dan yang paling besar adalah pembuat polisi.

Artikel ini mempunyai lima bahagian. Bahagian pertama, adalah bahagian pendahuluan yang menerangkan secara ringkas tentang kepentingan kajian, objektif, skop kajian. Kedua, sorotan literatur hasil kajian-kajian lepas yang berkaitan dengan efikasi kendiri dan penglibatan pelajar secara dalam talian. Pada bahagian ketiga, metodologi kajian dan kaedah yang digunakan akan dibentangkan bagi tujuan menganalisis data. Pada bahagian keempat, Data kajian akan dibentangkan dan dibincangkan dengan teliti dan dirumuskan sesuai dengan kajian-kajian semasa. Pada bahagian lima, atau bahagian akhir, implikasi kajian dan cadangan kajian lanjutan berkaitan dengan efikasi pelajar dan penglibatan pelajar.

\section{Sorotan Literatur}

\section{Konsep Efikasi Kendiri}

Efikasi kendiri dipelopori oleh Albert Bandura mempunyai kesan yang penting kepada motivasi, kesungguhan, keyakinan individu. Pajares (1997) mendapati efikasi kendiri boleh memberi impak kepada pilihan yang dibuat, usaha yang dilakukan, dan kecekalan hati menghadapi cabaran, rintangan, tekanan dan kebimbangan. Tambahan lagi, Wang dan Pape (2007), menyatakan bagi pelajar yang mempunyai efikasi kendiri yang tinggi didapati lebih berpotensi untuk berjaya dalam akademik mereka.

Efikasi kendiri mempunyai peranan penting dalam pembentukan personaliti pelajar dan pelaksanaan sesuatu tugasan walaupun dengan cabaran yang pelbagai. Bandura (1997) menyatakan efikasi kendiri adalah kepercayaan diri sendiri dalam melaksanakan tugasan atau aktiviti sehingga berjaya. Hal ini selaras dengan Shen et al. (2013) mendapati bahawa bagi pelajar efikasi kendiri yang tinggi, mereka lebih berpotensi untuk berjaya dan mudah berkomunikasi serta bekerjasama dengan rakan sekelas yang lain.

Efikasi kendiri juga mempunyai perkaitan dengan emosi. Jika individu mempunyai emosi yang positif, mereka mempunyai efikasi kendiri yang lebih tinggi terhadap perkara yang dilakukan mereka. Namun, sekiranya mereka selalu mengalami tekanan, efikasi kendiri mereka dalam aktiviti juga akan rendah (Bandura, 1977). Zheng et al. (2018) menyatakan efikasi kendiri mempengaruhi secara positif kepada pelajar dengan cara membantu mereka membuat keputusan dan meningkatkan keyakinan diri. Santrok (2004) menyatakan pelajar dengan efikasi kendiri yang baik cenderung untuk berusaha dengan tekun dan menyelesaikan masalah dengan baik, sementara pelajar dengan efikasi kendiri yang rendah cenderung untuk mengelakkan tugas yang sukar.

\section{Konsep Keterlibatan Pelajar}

Jeongju Lee et. al (2019) menerangkan maksud penglibatan pelajar adalah interaksi pelajar, tahap usaha menggunakan sumber pembelajaran bagi mengembangkan prestasi dan pengalaman pembelajaran. Dalam tinjauan literatur berkaitan, Fredricks, Blumenfeld dan Paris (2004) mengenal pasti tiga jenis penglibatan pelajar iaitu emosi, tingkah laku dan kognitif. Penglibatan tingkah laku adalah merangkumi aktiviti dan usaha pelajar, penglibatan emosi pula terdiri daripada motivasi, komitmen, dan rasa selesa dan rasa kebersamaan, manakala penglibatan kognitif melibatkan tahap 
usaha, kesediaan, dan sumber kognitif yang pelajar fokuskan untuk memperoleh pengetahuan dan kemahiran yang diperlukan (London, Downey, \& Mace, 2007).

Keterlibatan pelajar ketika dalam pembelajaran dalam talian boleh berlaku dalam kelas segerak dan kelas tidak segerak. Di dalam kelas segerak, pelajar boleh berinteraksi secara terus di dalam kelas dan mendapat respons dari pengajar secara langsung Manakala, kelas tidak segerak boleh dilaksanakan secara individu mengikut tarikh akhir yang telah ditetapkan oleh tenaga pengajar (Mark, 2016). Oleh itu, daripada penilaian guru melalui interaksi dan keterlibatan pelajar di dalam kelas segerak atau tidak segerak memberi peluang kepada tenaga pengajar untuk menginovasi dan tambah baik pengajaran berdasarkan interaksi dan penglibatan pelajar. Tambahan, dari Lehman \& Conceição, (2014) semasa merancang proses pengajaran, pengajar menetapkan objektif yang jelas, mempelbagaikan interaksi mengikut pelajar, dan memasukkan maklum balas sepanjang kursus untuk mewujudkan rasa keberadaan dan keterlibatan pelajar Kajian mengenai penglibatan pelajar dikuatkan lagi oleh Kuh (2009) keterlibatan pelajar dalam sesi pembelajaran mempunyai pengaruh positif terhadap pembelajaran dan prestasi.

\section{Efikasi Kendiri dan Keterlibatan}

Penglibatan pelajar adalah sangat penting dalam sesi pengajaran kerana penglibatan dilihat memberi kesan kepada kefahaman pelajar walaupun mereka mempunyai efikasi kendiri yang tinggi. Menurut Dörnyei (2000) pelajar yang mendapat skor yang tinggi dalam efikasi kendiri menghadapi cabaran dalam memahami subjek pelajaran jika mereka tidak terlibat aktif dalam sesi tersebut. Dalam kajian lain berkenan efikasi kendiri dan penglibatan, Dogan (2015) menyatakan penglibatan kognitif yang menjadi salah satu dimensi dalam penglibatan mampu meramal prestasi akademik. Selain itu, efikasi kendiri serta motivasi mampu meramal prestasi pelajar. Hal ini kerana, penyelidikan menunjukkan bahawa efikasi kendiri membolehkan pelajar untuk bekerjasama dan berinteraksi semasa proses pembelajaran dan meningkat penglibatan pelajar (Umbach \& Wawrzynski, 2005).

Tambahan pula, kejayaan akademik telah dikaitkan dengan penglibatan pelajar di dalam kelas. Menurut Lei et al. (2018) wujud korelasi positif yang kuat antara penglibatan pelajar secara keseluruhan dengan pencapaian akademik, dan analisis terhadap domain penglibatan tingkah laku, emosi, dan kognitif menunjukkan bahawa hampir semua mempunyai hubungan positif dengan keputusan akademik pelajar. Oleh itu, efikasi kendiri dan penglibatan pelajar perlu ditekankan dalam pembelajaran atas talian kerana terbukti berkesan daripada beberapa literatur sebelum ini.

\section{Model Efikasi Kendiri dan Keterlibatan Pelajar dalam Talian}

Rajah 1: Kerangka Konsep Kajian

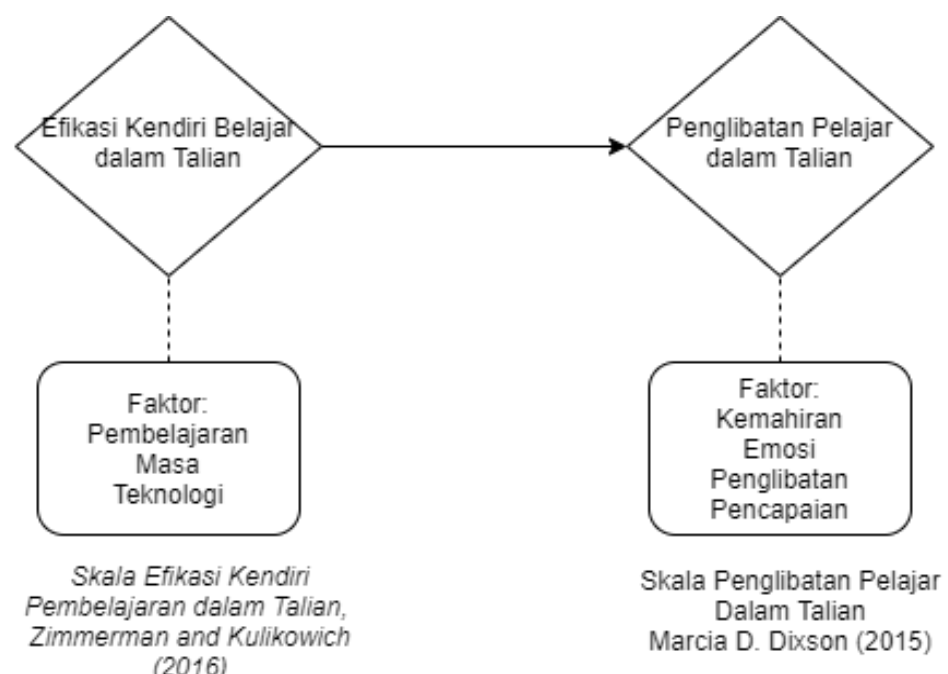

Sumber: Diadaptasi daripada Zimmerman dan Kulikowich (2016) serta Marcia (2015) 
Model yang dicadangkan disusun dari hasil kajian lepas oleh Zimmerman dan Kulikowich (2016) bagi skala efikasi kendiri pembelajaran dalam talian dan Marcia (2015) bagi skala penglibatan pelajar dalam talian. Model efikasi kendiri terdiri dari tiga dimensi yang terdiri dari pembelajaran, pengurusan masa dan penggunaan teknologi secara dalam talian. Bagi skala penglibatan pelajar terdiri dari empat dimensi, dimensi kemahiran, dimensi emosi, dimensi interaksi penglibatan dan dimensi prestasi. Model ini akan mengkaji lebih lanjut berkenaan efikasi kendiri dan penglibatan pelajar khususnya ketika pembelajaran dalam talian dijalankan sepanjang tempoh kawalan pergerakan bagi memastikan pembelajaran dalam talian menjadi alternatif terbaik dan relevan sepanjang pembelajaran dalam talian dijalankan.

\section{Metod Kajian}

Reka bentuk kajian menggunakan kaedah tinjauan. Menurut kajian Creswell (2014), tujuan pemilihan reka bentuk ini adalah untuk mendapatkan maklumat mengenai tingkah laku, sikap, pandangan dan ciri-ciri kumpulan atau sesuatu kumpulan, sambil menjimatkan masa, tenaga dan wang. Kaedah kajian berbentuk tinjauan digunakan dalam kajian ini bagi mendapatkan maklum balas mengenai efikasi kendiri pelajar belajar secara dalam talian dan keterlibatan pelajar. Populasi kajian ini adalah pelajar sarjana arus perdana di fakulti pendidikan UKM yang mengambil kursus secara atas talian sesi 2020/ 2021. Jumlah populasi pelajar adalah seramai 500 orang. Persampelan rawak sistematik dilaksanakan kepada responden dari populasi yang terdiri dari pelbagai bangsa, jantina, dan latar belakang. Menurut jadual Krejeie dan Morgan (1970) Jumlah responden yang sesuai untuk kajian ini adalah seramai 219 responden

Instrumen kajian diadaptasi dari kajian seperti berikut: Skala efikasi kendiri pembelajaran pelajar dalam talian oleh Zimmerman dan Kulikowich (2016) dan skala penglibatan pelajar dalam talian oleh Marcia (2015). Kajian rintis dijalankan kepada 30 pelajar berdasarkan Hill (1998) mencadangkan 10 hingga 39 peserta dalam kajian rintis kaji selidik.

Skala efikasi kendiri pembelajaran pelajar dalam talian oleh Zimmerman dan Kulikowich (2016) mempunyai 3 dimensi (suasana pembelajaran dalam talian, pengurusan waktu, penggunaan teknologi) dan mempunyai 22 soalan. Cronbach's alpha dijalankan kepada soalan ini untuk menguji kesahan dalaman untuk setiap sub-skala. Kesahan adalah dalam 0.843 hingga 0.890. Soal selidik ini menggunakan skala likert bagi mengukur pandangan responden terhadap kenyataan yang diberikan. Skala likert itu adalah seperi berikut 1: Sangat tidak setuju; 2: Tidak Setuju; 3: tidak pasti; 4: Setuju; 5: Sangat setuju. Cronbach's alpha selepas soalan ini diadaptasi adalah 0.929.

Skala penglibatan pelajar dalam talian oleh Marcia (2015) mempunyai empat dimensi (kemahiran, emosi, penglibatan, dan prestasi) dan 19 soalan. Cronbach's alpha untuk kajian lepas adalah .86, yang menunjukkan soalan ini mempunyai kesahan dalaman yang baik. Soalan yang diberikan adalah soalan berkaitan penglibatan pelajar dalam talian. Skala Likert digunakan bagi menilai tahap penglibatan pelajar seperti berikut: (1: sama sekali bukan karakter saya; 2: bukan karakter saya; 3: karakter saya secara sederhana; 4: karakter saya; 5: sangat menggambarkan karakter saya). Cronbach's alpha selepas soalan ini diadaptasi adalah 0.928 .

Dalam menjalankan penyelidikan ini, penyelidik melakukan beberapa prosedur. Prosedur pertama membincangkan masalah yang dihadapi dan tajuk kajian yang dicadangkan bersama penyelia. Seterusnya, selepas mendapat kelulusan pengkaji meneruskan pencarian sumber-sumber berkaitan kajian. Soal selidik skala efikasi kendiri pembelajaran pelajar dalam talian oleh Zimmerman dan Kulikowich (2016) dan skala penglibatan pelajar dalam talian oleh Marcia (2015) kedua-dua soal selidik ini telah diterjemahkan dari bahasa Inggeris ke Bahasa Malaysia oleh penterjemah. Soal selidik versi Bahasa Melayu disahkan semula oleh pakar bahasa dan pensyarah psikologi pendidikan Universiti Kebangsaan Malaysia sebelum kemudiannya disediakan untuk peserta ujian rintis.

Setelah mendapat analisa kajian rintis, soalan akan diselaraskan mengikut hasil kesahan dan kebolehpercayaan dari kajian rintis dan soal selidik bersedia untuk diberikan kepada peserta kajian 
DOI: https://doi.org/10.47405/mjssh.v6i8.945

sebenar. Soalan disusun dan dibentuk menggunakan Google Form, kemudian diedarkan melalui email kepada semua responden yang terpilih. Sesi ini dijangkakan mengambil masa selama sebulan.

Analisa Pakej Statistik Sains Sosial (SPSS) versi 23 digunakan untuk menganalisis data kajian efikasi kendiri pelajar dan penglibatan pelajar secara dalam talian. Analisis deskriptif digunakan, termasuk min dan sisihan piawai. Analisis infrensi juga digunakan antaranya ujian korelasi pearson juga digunakan untuk menguji hubungan antara pemboleh ubah yang dikaji.

\section{Hasil Kajian}

Kaji selidik ini telah dijalankan pada 219 pelajar sarjana Fakulti Pendidikan Universiti Kebangsaan Malaysia dari pelbagai kursus. Berdasarkan jadual 1 yang berkaitan profil responden, majoriti peserta kaji selidik ini adalah dari kalangan perempuan (81.7\%) manakala selebihnya adalah lelaki (18.3\%). Umur responden adalah dari julat umur 21 hingga 60 tahun, dan majoriti responden dari kumpulan umur 21-30 tahun, sebanyak 121 responden (55.3\%) manakala kumpulan umur yang lain adalah sebanyak 98 responden (44.7\%). Sebilangan besar dari bilangan responden adalah dari mod C kerja kursus 119 (54.3\%) dan respons yang belajar secara sepenuh masa adalah seramai 162 (74\%). Bagi responden mengikut tahun belajar, majoriti pelajar adalah dari pelajar tahun 2 sebanyak $103(47 \%)$, manakala tahun 1, 83 (37.9\%), tahun 3 dan ke atas adalah 30 (13.7\%). Sebanyak 159 (72.6\%) dari 219 pelajar mempunyai skor PNGK di atas 3.51 - 4.00, manakala responden yang mendapat nilai PNGK 3.5 ke bawah adalah 37 pelajar (16.9\%).

Jadual 1: Profil Responden ( $\mathrm{n}=219)$

\begin{tabular}{|c|c|c|c|}
\hline & & Kekerapan & Peratusan \\
\hline \multirow{2}{*}{ Jantina } & Lelaki & 40 & 18.3 \\
\hline & Perempuan & 179 & 81.7 \\
\hline \multirow[t]{4}{*}{ Umur } & 21-30 tahun & 121 & 55.3 \\
\hline & $31-40$ tahun & 71 & 32.4 \\
\hline & 41- 50 tahun & 26 & 11.9 \\
\hline & 51- 60 tahun & 1 & .5 \\
\hline \multirow[t]{3}{*}{ Mod } & Mod A: Kajian Penuh & 8 & 3.7 \\
\hline & $\begin{array}{l}\text { Mod B: Campuran (kajian } \\
\text { dan kerja kursus) }\end{array}$ & 92 & 42.0 \\
\hline & Mod C: Kerja Kursus & 119 & 54.3 \\
\hline \multirow[t]{2}{*}{ Pelajar } & Separuh masa & 57 & 26.0 \\
\hline & Sepenuh masa & 162 & 74.0 \\
\hline \multirow[t]{5}{*}{ Tahun } & Pertama & 83 & 37.9 \\
\hline & Kedua & 103 & 47.0 \\
\hline & Ketiga & 25 & 11.4 \\
\hline & Keempat & 4 & 1.8 \\
\hline & Kelima ke atas & 1 & .5 \\
\hline \multirow[t]{5}{*}{ PNGK } & $0-2.00$ & 4 & 1.8 \\
\hline & $2.01-2.50$ & 1 & .5 \\
\hline & $3.01-3.50$ & 32 & 14.6 \\
\hline & $3.51-4.00$ & 159 & 72.6 \\
\hline & Tiada & 23 & 10.5 \\
\hline
\end{tabular}


DOI: https://doi.org/10.47405/mjssh.v6i8.945

Jadual 2: Skor min dan sisihan piawai bagi efikasi kendiri pelajar secara keseluruhan

\begin{tabular}{lcccc} 
& $\mathbf{N}$ & Mean & Sisihan Piawai & Tahap \\
\hline $\begin{array}{l}\text { Efikasi_Kendiri } \\
\text { (Keseluruhan) }\end{array}$ & 219 & 3.9834 & .46753 & Tinggi \\
$\begin{array}{l}\text { Pembelajaran } \\
\text { Teknologi }\end{array}$ & 219 & 3.8607 & & Tinggi \\
Masa & 219 & 3.9370 & .53442 & Tinggi \\
\hline
\end{tabular}

Analisis deskriptif dalam jadual 2 adalah nilai min dan sisihan piawai keseluruhan dan bagi setiap dimensi efikasi kendiri yang digunakan. Hasil analisa, efikasi kendiri belajar secara dalam talian keseluruhannya menunjukkan tahap tinggi $(\mathrm{min}=3.98$, s. $\mathrm{p}=0.47$ ). Terdapat 3 dimensi di bawah efikasi kendiri (Pembelajaran, Teknologi dan Masa). Bagi dimensi pembelajaran pada tahap yang tinggi dengan nilai min 3.86 dan sisihan piawai 0.53. Manakala nilai min dan sisihan piawai teknologi (min= 3.93 , s.p=0.62) dan masa $(\min =4.19$, s.p $=0.47)$.

Jadual 3: Skor min dan sisihan piawai dimensi penglibatan pelajar dalam talian secara keseluruhan

\begin{tabular}{lcclc} 
& $\mathbf{N}$ & Mean & Sisihan Piawai & Tahap \\
\hline $\begin{array}{l}\text { Penglibatan } \\
\text { (Keseluruhan) }\end{array}$ & 219 & 3.9623 & .49273 & Tinggi \\
Kemahiran & & & & \\
Emosi & 219 & 3.8425 & .56681 & Tinggi \\
Keterlibatan & 219 & 4.0237 & .58559 & Tinggi \\
Prestasi & 219 & 3.9688 & .59681 & Tinggi \\
\hline
\end{tabular}

Analisis data deskriptif dari jadual 3, menunjukkan penglibatan (keseluruhan) pelajar adalah tinggi dengan nilai $\min =3.96$ dan sisihan piawai $=0.49$. Bagi dimesi kemahiran $(\min =3.84$, s.p $=0.56)$, emosi $(\min =4.02$, s.p $=0.59)$ dan keterlibatan $(\min =3.96$, s.p $=0.60)$. Manakala dimensi prestasi berada pada tahap tertinggi berbanding konstruk lain dengan nilai min 4.15 dan sisihan piawai 0.63 .

Jadual 4: Ujian Kenormalan

\begin{tabular}{|c|c|c|c|c|c|c|c|c|c|c|}
\hline & \multicolumn{3}{|c|}{ Kolmogorov-Smirnov } & \multicolumn{2}{|c|}{ Shapiro-Wilk } & & \multicolumn{2}{|c|}{ Skewness } & \multicolumn{2}{|c|}{ Kurtosis } \\
\hline & & & & & & & Statistic & Std & Statist & Std \\
\hline & Statistic & $\mathrm{df}$ & Sig. & Statistic & $\mathrm{df}$ & Sig. & & & & $\mathrm{r}$ \\
\hline $\begin{array}{l}\text { Efikasi } \\
\text { Kendiri }\end{array}$ & .040 & 219 & $.200^{*}$ & .989 & 219 & .098 & .050 & .164 & -.424 & .327 \\
\hline Penglibatan & .051 & 219 & $.200^{*}$ & .992 & 219 & .235 & -.101 & .164 & -.287 & .327 \\
\hline
\end{tabular}

Ujian Kolmogorov-Smirnov dan Shapiro-Wilk menunjukkan nilai $\mathrm{p}>0.05$ yang memberi makluman bahawa data adalah dalam taburan normal.

Dapatan kajian yang ditunjukkan dalam Jadual Ujian Korelasi , mendapati terdapat hubungan yang signifikan antara efikasi kendiri dan penglibatan pelajar dalam talian $[\mathrm{r}(219)=0.611, \mathrm{p}<0.01]$. Ini bermakna terdapat hubungan positif linear antara tahap efikasi pelajar dengan tahap keterlibatan pelajar dalam kelas atas talian. Interpretasi hubungan antara pemboleh ubah sederhana kuat $(\mathrm{r}=$ 0.634). Oleh itu, hipotesis nul adalah gagal diterima. 
DOI: https://doi.org/10.47405/mjssh.v6i8.945

Jadual 5: Ujian Korelasi Pearson

\begin{tabular}{llc}
\hline & & Keterlibatan Pelajar \\
\hline \multirow{2}{*}{ Efikasi Kendiri } & Pearson Correlation & $.611^{* *}$ \\
& Sig. (2-tailed) & .000 \\
& $\mathrm{~N}$ & 219 \\
\hline
\end{tabular}

**Korelasi signifikan pada 0.01 level (2-ekor)

Berdasarkan ujian di Jadual 6, pelajar lelaki menunjukkan min skor efikasi kendiri $[\mathrm{min}=3.93( \pm$ $0.07)]$ yang sama dengan pelajar perempuan $[\min =3.99( \pm 0.35)] ; \mathrm{t}(217)=0.873, \mathrm{p}>0.05[95 \% \mathrm{CI}=$ -0.228 hingga 0.102]. Manakala bagi skor penglibatan, pelajar lelaki menunjukkan min skor sama[min $=3.95( \pm 0.08)]$ dengan pelajar perempuan $[\mathrm{min}=3.97( \pm .04)] ; \mathrm{t}(217)=, \mathrm{p}>0.05[95 \% \mathrm{CI}=-0.195$ hingga 0.152$]$.

Jadual 6 : Ujian T sampel bebas

\begin{tabular}{lccccc}
\hline & Jantina & N & Min & Sisihan Piawai & Selisihan piawai \\
\hline Mean efikasi & Lelaki & 40 & 3.9318 & .47080 & .07444 \\
kendiri & Perempuan & 179 & 3.9949 & .46733 & .03493 \\
Mean penglibatan & Lelaki & 40 & 3.9447 & .49630 & .07847 \\
& Perempuan & 179 & 3.9662 & .49324 & .03687 \\
\hline
\end{tabular}

\section{Ujian T sampel bebas}

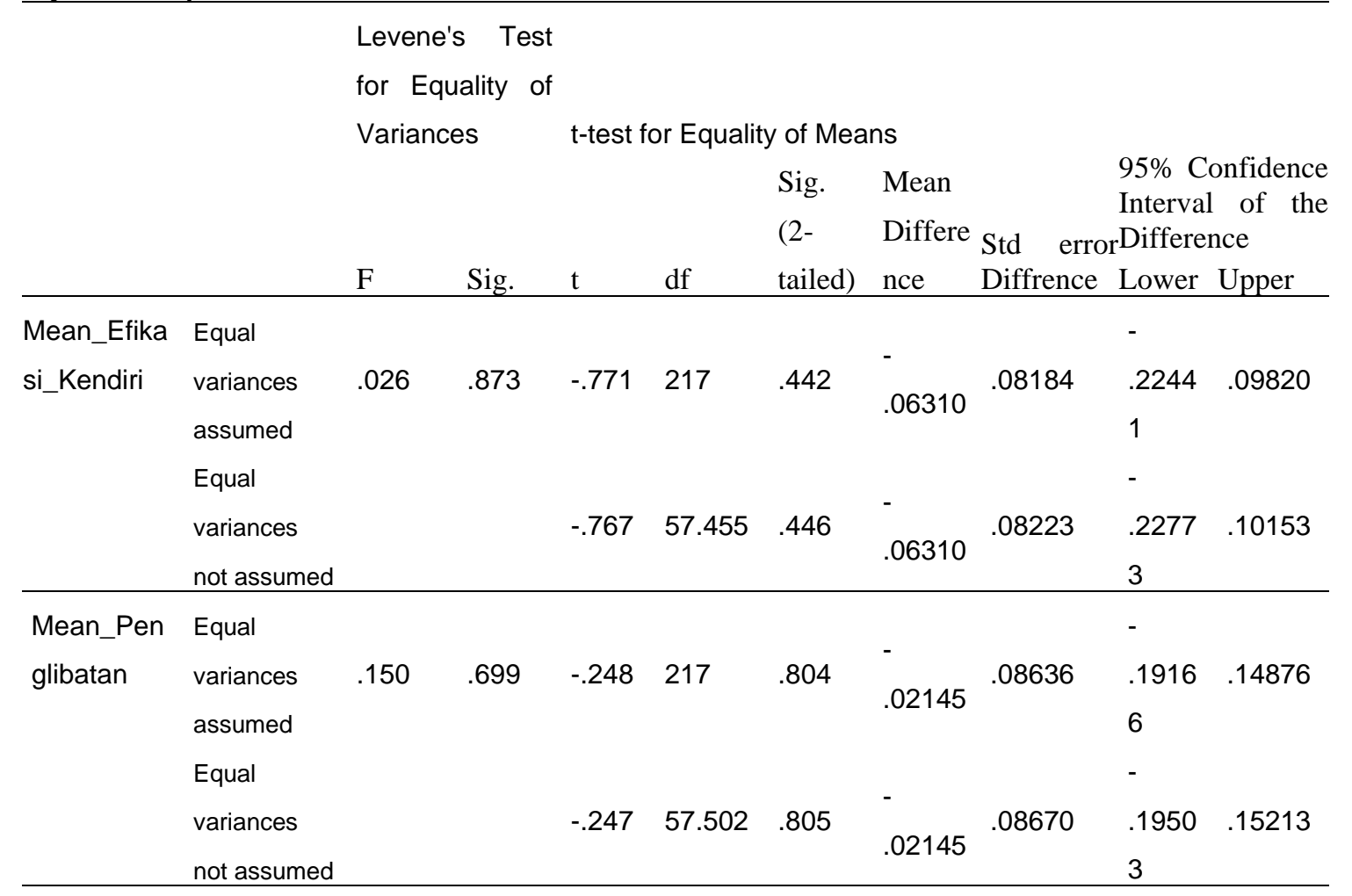




\section{Perbincangan Kajian}

Kajian berkaitan efikasi kendiri dan keterlibatan pelajar belajar dalam talian sepanjang tempoh pandemik covid-19. Melalui kajian ini, dimensi efikasi kendiri dan penglibatan secara dalam talian, dinilai bagi melihat interaksi antara dua pemboleh ubah ini mempengaruhi pembelajaran dalam talian.

Secara keseluruhan bagi analisa efikasi kendiri menunjukkan tahap yang tinggi. Hal ini kerana, responden dari kalangan pelajar telah didedahkan dengan penggunaan platform dalam talian sejak dari awal kemasukan dan responden yang kebanyakannya adalah tahun 2, telah mahir dan berpengalaman belajar secara dalam talian sejak pandemik yang lebih setahun telah berlalu. Dapatan ini selari oleh Law et al (2010), e-pembelajaran yang diurus dengan baik mampu meningkatkan efikasi kendiri untuk pembelajaran dalam talian manakala Song et al. (2011) dan Chang et al. (2014) menyatakan pengalaman dan kebolehcapaian menggunakan sistem dalam talian secara langsung memberi kesan kepada efikasi kendiri pelajar ketika pembelajaran dalam talian.

Bahagian dimensi pembelajaran di dalam efikasi kendiri, mengenal pasti tahap kebolehan responden dalam menggunakan teknologi dalam pembelajaran sama ada dari segi komunikasi, kemampuan belajar secara dalam talian, dan kemampuan untuk kekal fokus. Bagi dimensi pembelajaran dalam talian, kajian ini menunjukkan responden mempunyai tahap yang tinggi. Hal ini demikian kerana, kemahiran yang baik mampu membantu pelajar menggunakan platform yang disediakan institusi untuk sesi pembelajaran. Menurut Bates dan Khasawneh (2007), efikasi kendiri pelajar kolej, kemahirankemahiran yang dipelajari melalui pengalaman dan komunikasi mempunyai kesan yang signifikan kepada efikasi kendiri.

Dimensi yang seterusnya adalah berkaitan dengan masa. Tahap pengurusan masa responden diukur dengan cara pengurusan masa, perancangan dan kemampuan responden mengikuti tarikh akhir dan perancangan yang telah disusun. Bagi dimensi ini, responden mendapatkan tahap yang tinggi. Hal ini disebabkan, masa gagal diurus dengan baik disebabkan kekurangan kemahiran dalam menggunakan teknologi menyebabkan pengurusan masa kurang berkesan dan efektif. Hujah ini disokong oleh Salwati dan masliza (2017) bagi pelajar yang lemah pengurusan masa, gagal menyenaraikan aktiviti yang perlu dilakukan sepanjang tempoh seminggu mampu memberi kesan kepada pembelajaran.

Teknologi merupakan dimensi yang terakhir yang diukur dalam efikasi kendiri. Bagi dimensi ini, responden dinilai melalui kecekapan menggunakan teknologi yang pelbagai untuk pembelajaran dan komunikasi dan kemampuan mereka mengurus masalah teknikal dengan sendiri. Dimensi ini juga mendapat skor yang tinggi oleh responden. Hal ini kerana, penggunaan teknologi dengan optimum mampu menjadi alat membantu proses pembelajaran berjalan dengan berkesan dan efisien. Hal ini selari dengan kajian oleh Bates and Khasawneh (2007) yang menyatakan efikasi kendiri dalam menggunakan teknologi menjadi peramal yang baik untuk prestasi pelajar dalam kursus. Manakala kajian Larocca (2017) dan Cusso-Calabuig et al. (2018) menyatakan pelajar yang menggunakan teknologi dengan baik mampu memberi kesan emosi yang baik (seronok) dan efikasi kendiri mereka meningkat.

Dapatan kajian menunjukkan skor efikasi kendiri antara pelajar lelaki dan perempuan adalah sama. Hal ini kerana, gender tidak mempunyai hubungan ke atas efikasi kendiri secara langsung berbanding dengan pemboleh ubah seperti sokongan sosial, regulasi kendiri dan motivasi. Hal ini selari dengan kajian Yavuzalp dan Bahcivan (2020) mendapati tidak terdapat perbezaan dalam jumlah skor efikasi kendiri pelajar universiti dari segi jantina. Namun dalam kajian yang lain, dijalankan oleh Chu (2010), dalam model gender, terdapat perbezaan antara lelaki dan perempuan, efikasi kendiri lelaki lebih rendah berbanding wanita dalam pembelajaran dalam talian. Bagi lelaki dan perempuan, sokongan sosial merupakan sumber yang paling berkesan membantu individu meningkatkan efikasi kendiri dan mengurus tekanan.

Mean skor efikasi kendiri mengikut umur menunjukkan nilai yang sama. Hal ini kerana, pihak universiti telah mendedahkan penggunaan platform dalam talian dengan baik dan sesuai bagi semua peringkat umur pelajar. Namun, bagi kajian yang berkaitan dengan umur, Chua (2010), menyatakan 
efikasi kendiri dalam pembelajaran dalam talian mempunyai kesan yang besar ke atas pelajar yang berumur 50 ke atas. Sokongan keluarga dilihat memberi kesan terus kepada efikasi kendiri pelajar dalam pembelajaran dalam talian.

Skor min penglibatan pelajar secara keseluruhan menunjukkan tahap yang tinggi. Keterlibatan bukan hanya menyiapkan tugasan kerana situasi ini akan membezakan antara rutin tanpa memahami dan melibatkan dalam pengajaran tersebut. Terdapat empat dimensi di dalam konstruk penglibatan yang terdiri dari dimensi kemahiran, emosi, keterlibatan dan prestasi.

Dimensi kemahiran, berkaitan kemahiran yang digunakan sepanjang kursus dalam talian berlangsung. Mean skor dimensi kemahiran adalah tinggi. Hal ini kerana, pelaksanaan kelas yang menekankan kemahiran pelajar seperti kemahiran menghafal, memahami, praktikal, dan analisis mampu menarik minat pelajar untuk terlibat dalam pembelajaran. Hujah ini disokong oleh Xu dan Gong (2009), yang menyatakan kemahiran memahami dan menghafal memerlukan penglibatan emosi dan kognitif dalam budaya Asia, dan bagi budaya Barat, pembelajaran yang menekankan kemahiran amali dan operasi pada pelajar ditekankan. Oleh itu, kemahiran ini lebih relevan dengan penglibatan tingkah laku, dan sebahagian besarnya kemahiran inilah yang menentukan tahap penglibatan dan memberi kesan kepada akademik dan pencapaian pelajar.

Dimensi emosi pula berkaitan cara responden mengekalkan minat kepada pembelajaran dan kursus agar terus relevan dalam kehidupan. Kajian ini menunjukkan tahap yang tinggi untuk dimensi emosi. Hal ini tercetus apabila sesi pembelajaran yang kreatif mampu memberi reaksi emosi yang positif kepada pelajar. Hal ini disokong Hao Li (2017) yang mendapati penglibatan emosi terhadap pelajar terdiri daripada reaksi emosi kepada sesuatu yang berkaitan dengan minat. Selari dengan itu, kajian dari Pellas (2014), menyatakan terdapat korelasi antara metakognisi, regulasi kendiri, efikasi kendiri dan penglibatan emosi. Tambahan dari kajian lain berkaitan motivasi, Özhan dan Kocadere (2020) menyatakan, penglibatan emosi mempunyai perkaitan dengan motivasi untuk berjaya di dalam pembelajaran atas talian.

Dimensi keterlibatan adalah berkenaan cara responden melibatkan diri sepanjang proses pembelajaran. Kajian menunjukkan skor pada tahap yang tinggi untuk dimensi keterlibatan ini. Kursus yang disediakan memerlukan pelajar untuk terlibat secara segerak dan tidak segerak yang membantu, memaksimumkan keterlibatan pelajar dalam sesi pembelajaran yang lebih fleksibel. Hal ini mengukuhkan kajian Parker and Martin (2010) yang mendapati bahawa integrasi pertemuan segerak dalam kursus dalam talian dapat memberi manfaat kepada pelajar kerana meningkatkan interaksi pelajar. Pelajar dapat mengembangkan kemahiran teknologi mereka, dan mereka mempunyai peluang untuk berinteraksi dengan pengajar. Oleh itu, pembelajaran segerak dan tidak segerak membolehkan perbincangan yang tersusun mengenai kursus.

Dimensi yang terakhir melibatkan prestasi, yang berkaitan keyakinan responden ketika melakukan ujian dan mendapat gred yang baik. Responden mendapat skor tinggi bagi dimensi ini. Hal ini kerana, dengan penglibatan aktif sama ada melalui perilaku, emosi, penglibatan kognitif, pelajar akan berasa lebih berkeyakinan dalam ujian dan efikasi kendiri mereka meningkat. Ini selaras dengan kajian Lei et al (2018) terdapat hubungan positif yang kuat antara penglibatan pelajar secara keseluruhan dengan pencapaian akademik. Analisis terhadap domain perilaku, emosi, dan penglibatan kognitif menunjukkan bahawa hampir semua mempunyai hubungan positif dengan pencapaian akademik pelajar. Tambahan dari Zimmerman and Kulikowich (2016) menyatakan bagi pelajar yang mempunyai keyakinan yang baik semasa pembelajaran dalam talian berpotensi untuk berjaya di dalam kursus atas talian.

Kajian mendapati tiada perbezaan yang signifikan bagi mean skor penglibatan responden lelaki dan perempuan. Hal ini kerana, akses, kemudahan dan kemahiran dalam menggunakan teknologi mengecilkan jurang penglibatan pelajar antara pelajar lelaki dan perempuan. Hal ini selari dengan Beer, et. al (2010) menyatakan kurangnya perbezaan antara skor penglibatan pelajar antara gender adalah disebabkan kebolehcapaian kepada teknologi yang lebih mudah. Manakala, menurut kajian yang menyatakan perbezaan penglibatan dari segi gender adalah dari Martin dan Bolliger (2018) yang 
menyatakan pelajar perempuan dilihat menerokai dengan lebih mendalam subjek yang dipelajari secara dalam talian berbanding pelajar lelaki.

Kajian menunjukkan terdapat hubungan antara efikasi kendiri dan penglibatan dalam pembelajaran atas talian. Hal ini kerana, apabila pelajar yakin serta mahir dalam menggunakan teknologi yang diperlukan dalam pembelajaran atas talian, ini akan memudahkan mereka untuk berinteraksi dan terlibat secara langsung dalam sesi pembelajaran. Dapatan ini menunjukkan efikasi kendiri mempunyai hubungan dengan penglibatan pelajar sewaktu pembelajaran dalam talian. Dapatan ini selaras dengan Wolverton et al (2020) yang menyatakan efikasi kendiri mempunyai korelasi kepada penglibatan pelajar dan, selanjutnya, penglibatan pelajar mempengaruhi tahap kepuasan mengikut kumpulan.

\section{Kesimpulan}

Rumusan bagi kajian ini, pembelajaran dalam talian menjadi alternatif kepada pembelajaran bersemuka sewaktu kawalan pergerakan disebabkan pandemik Covid-19. Elemen efikasi kendiri mempunyai korelasi yang baik dengan penglibatan pelajar ketika pembelajaran dalam talian. Hal ini menunjukkan, keperluan untuk membina meningkatkan efikasi kendiri pelajar melalui dimensi-dimensi di dalamnya (Pembelajaran, Teknologi dan Masa) agar mereka mampu terlibat dengan aktif dalam kelas secara dalam talian sama ada segerak atau tidak segerak. Selain itu, pembelajaran dalam talian perlu dijadikan antara medium pembelajaran alternatif dan pelengkap buat pembelajaran bersemuka kerana zaman milenium ini tidak dapat lari dari penggunaan teknologi. Pembelajaran dalam talian sewaktu pandemik ini boleh dijadikan pemangkin dan pemula bagi pembangunan pembelajaran dalam talian agar mampu berdiri sebagai medium yang terbukti berkesan untuk pembelajaran.

Antara limitasi kajian ini adalah, skop kajian hanya terhad kepada pelajar sarjana Fakulti Pendidikan Universiti Kebangsaan Malaysia yang mengambil kursus secara dalam talian sahaja. Antara limitasi kedua adalah, perbezaan pelajar lelaki dan perempuan yang terlalu besar dan juga perbezaan antara kumpulan umur, yang memberikan kesan kepada kajian yang berkaitan perbezaan jantina dan umur. Diharap, kajian akan datang mampu mengaitkan hubungan efikasi kendiri, penglibatan, regulasi kendiri, motivasi dan prestasi. Selain itu, kajian akan datang mampu untuk membesarkan skop kajian pada skala yang lebih besar.

\section{Rujukan}

Bandura, A. (1977). Self-Efficacy: Toward A Unifying Theory Of Behavioral Change. Psychological Review, 84, 191-215.

Bandura, A. (1997). Self-Efficacy. The Exercise Of Control. New York: W.H.Freeman and Company.Emory University, Division of Educational Studies, Information on Self-Efficacy: A Community of Scholars.

Bates \& Khasawneh. (2007). Self-efficacy and college student' perceptions and use of online learning systems. Computers in Human Behavior, 23, 175-191, doi: 10.1016/j.chb.2004. 04.00

Beer Clark \& Jones. (2010). Indicators of engagement. In C.H. Stee, M.J. Keppell, P. Geric \& Housego (Eds.), Curriculum, technology \& transformation for an unknown future. Proceedings ascilite Sydney 2010, 75-86. Retrieved from http://www.ascilite.org.au/conferences/sydney10/procs/Beer-full.pdf

Carey. (2020). Is Everybody Ready For The Big Migration To Online College? Actually, No. The New York Times. https://www.nytimes.com

Chang, H., Wang, C., Lee, M., Wu, H., Liang, J., Lee, S., Chiou, G., Lo, H., Lin, J., Hsu, C., Wu, Y., Chen, S., Hwang, F. and Tsai, C., (2014). A review of features of technology-supported learning environments based on participants' perceptions. Computers in Human Behavior, 53, 223-237.

Chu, R. J. (2010). How family support and Internet self-efficacy influence the effects of elearning among higher aged adults-Analyses of gender and age differences. Computers \& Education, 55, 255-264 https://doi.org/10.1016/j.compedu.2010.01.011 
DOI: https://doi.org/10.47405/mjssh.v6i8.945

Comer, D. R., Lenaghan, J. A., \& Sengupta, K. (2015). Factors That Affect Students' Capacity To Fulfill The Role Of Online Learner. Journal of Education for Business, 90, 145-155.

Cusso-Calabuig, R., Farran, X.C. and Bosch-Capblanch, X. (2018). Effects of intensive use of computers in secondary school on gender differences in attitudes towards ICT: a systematic review. Education and Information Technologies, 23, 2111-2139, doi: 10.1007/s10639- 0189706-6

Dixson, Marcia. D. (2015). Measuring student engagement in the online course: The Online Student Engagement scale (OSE). Online Learning, 19(4).

Dogan, U. (2015). Student engagement, academic self-efficacy, and academic motivation as predictors of academic performance. The Anthropologist, 20(3), 553-561

Dörnyei Z. (2000). Motivation in action: Towards a process oriented conceptualization of student motivation. British Journal of Educational Psychology, 70, 519-538

Fredricks J.A., Blumenfeld P.C., Paris A.H. (2004). School engagement: potential of the concept, state of the evidence. Review of Educational Research, 74(1):59-109

Gilbert, P. K., \& Dabbagh, N. (2005). How to structure online discussions for meaningful discourse: A case study. British Journal of Educational Technology, 36(1), 5-18. doi:10.1111/j.14678535.2005.00434.x

Hill, R. (1998). What sample size is "enough" in internet survey research? Interpersonal Computing and Technology: An Electronic Journal for the 21st Century, 6(3-4).

$\mathrm{Hu}, \mathrm{M} .$, \& Li, H. (2017). Student engagement in online learning: A review. In 2017 International Symposium on Educational Technology (ISET) (pp. 39-43). IEEE.

Hung, M., Chou, C., Chen, C., \& Own, Z. (2010). Learner readiness for online learning: Scale development and student perceptions. Computers and Education, 55(3), 1080-1090. doi: 10.1016/j.compedu.2010.05.004

Krejeie, R. V. dan Morgan, DW. (1970). Determining Sample Size For Research.

Kuh, G. D. (2009). The national survey of student engagement: Conceptual and empirical foundations. New directions for institutional research, 141, 5-20.

LaRocca, B. (2017). Self-efficacy toolkit. Transforming education, available at: https://www. transformingeducation.org/self-efficacy-toolkit/.

Law, K.M.Y., Lee, V.C.S. and Yu, Y.T. (2010). Learning motivation in e-learning facilitated computer programming courses, Computers and Education, 55, 218-228, doi: 10.1016/j.compedu. 2010.01.007.

Lee, J., Song, H. D., \& Hong, A. J. (2019). Exploring factors, and indicators for measuring students' sustainable engagement in e-learning. Sustainability, 11(4), 985.

Lei, H., Cui, Y., \& Zhou, W. (2018). Relationships between student engagement and academic achievement: A meta-analysis. Social Behavior and Personality: an international journal, 46(3), 517-528.

London, B., Downey, G., \& Mace, S. (2007). Psychological theories of educational engagement: A multi-method approach to studying individual engagement and institutional change. Vand. $L$. Rev., 60, 455.

Martin, F., \& Bolliger, D. U. (2018). Engagement matters: Student perceptions on the importance of engagement strategies in the online learning environment. Online Learning, 22(1), 205-222.

Özhan, Ş. Ç., \& Kocadere, S. A. (2020). The effects of flow, emotional engagement, and motivation on success in a gamified online learning environment. Journal of Educational Computing Research, 57(8), 2006-2031.

Pajares, F., \& Valiante, G. (1997). Influence of self-efficacy on elementary students' writing. The Journal of Educational Research, 90(6), 353-360.

Parker, M., \& Martin, F. (2010). Using virtual classrooms: Student perceptions of features and characteristics in an online and a blended course. Journal of Online Learning and

Pellas. (2014). The influence of computer self-efficacy, metacognitive self-regulation and self-esteem on student engagement in online learning programs: Evidence from the virtual world of Second Life. Computers in Human Behavior, 35, 157-170.

R.Radhal, K.Mahalakshmi , Dr.V.Sathish Kumar, Dr.AR.Saravanakuma. (2020). E-Learning during Lockdown of Covid-19 Pandemic: A Global Perspective. International Journal of Control and Automation, 13(4), 1088-109 
DOI: https://doi.org/10.47405/mjssh.v6i8.945

Ramsin, A., \& Mayall, H. J. (2019). Assessing Esl Learners'online Learning Self-Efficacy In Thailand: Are They Ready?. Journal of Information Technology Education, 18.

Reychav, I., Ndicu, M. and Wu, D. (2016). Leveraging social networks in the adoption of mobile technologies for collaboration. Computers in Human Behavior,58, 443-453, doi: 10. 1016/j.chb.2016.01.011

Saad, N., \& Sankaran, S. (2020). Technology proficiency in teaching and facilitating. In Oxford Research Encyclopedia of Education.

Salwati. A \& Masliza M.J. (2017). Pengurusan Masa: Faktor Kemerosotan Pencapaian Pelajar JKE Bagi Kursus Electrical Technology (DET1013). National Innovation and Invention Competition Through Exhibition (iCompEx'17).

Scholl, M. B., Hayden, S. C., \& Clarke, P. B. (2017). Promoting optimal student engagement in online counseling courses. The Journal of Humanistic Counseling, 56(3), 197-210.

Schunk, D. H. (1990). Introduction to the special section on motivation and efficacy. Journal of Educational Psychology, 82(1), 3.

Shen, D., Cho, M., Tsai, C., \& Marra, R. (2013). Unpacking Online Learning Experiences: Online Learning Self-Efficacy And Learning Satisfaction. Internet and Higher Education, 19, 10-17. doi: 10.1016/j.iheduc.2013.04.001

Umbach, P. D., \& Wawrzynski, M. R. (2005). Faculty do matter: The role of college faculty in student learning and engagement. Research in Higher education, 46(2), 153-184.

Wang, C., \& Pape, S. J. (2007). A probe into three Chinese boys' self-efficacy beliefs learning English as a second language. Journal of Research in Childhood Education, 21(4), 364-377.

Wolverton, C. C., Hollier, B. N. G., \& Lanier, P. A. (2020). The impact of computer self efficacy on student engagement and group satisfaction in online business courses. Electronic Journal of $e$ Learning, 18(2), 175-188.

$\mathrm{Xu}, \mathrm{X} .$, \& Gong, S. (2009). Academic emotions and its influencing factors.

Yavuzalp, N., \& Bahcivan, E. (2020). The online learning self-efficacy scale: its adaptation into Turkish and interpretation according to various variables. Turkish Online Journal of Distance Education, 21(1), 31-44.

Zepke, N. and Leach, L. (2010). Improving student engagement: ten proposals for action. Active Learning in Higher Education, 11, 167-177.

Zheng L, Dong Y, Huang R, Chang C Y and Bhagat K K. (2018). Investigating The Interrelationships Among Conceptions Of Approaches To And Self-Efficacy In Learning Science. International Journal of Science Education, 40(2), 139-158

Zimmerman, W. A., \& Kulikowich, J. M. (2016). Online Learning Self-Efficacy In Students With And Without Online Learning Experience. American Journal of Distance Education, 30(3), 180191.https://doi.org/10.1080/08923647.2016.1193801 